\title{
La irradiación de la normatividad constitucional en el ámbito de la legislacion civil: los derechos del ciudadano frente a los poderes económicos privados
}

\author{
The Irradiation of the Constitutional Norms \\ in the Field of Civil Law: The Rights of \\ Citizens Against the Private Economic Power
}

Fecha de recepción: 3 de junio de 2009

Fecha de aprobación: 23 de septiembre de 2009

\begin{abstract}
Álvaro EcheVerri Uruburu*
Las innovaciones técnicas extienden al conjunto del planeta las relaciones sociales de producción y de intercambio de bienes y servicios. El sistema de relaciones socioeconómicas así mundializadas es capitalista. Sus efectos son los de toda economía capitalista: La agravación de las desigualdades sociales.

Sin regulación política, solamente se pueden derivar crisis y conflictos sociales internacionales. La economía mundial solamente podrá evitar o superar esas crisis y conflictos en la medida en que sea gobernada

y reglada según principios de justicia social (subrayados nuestros)

(Jean-William Lapierre, Qué es ser ciudadano, 2003).
\end{abstract}

Las sociedades que quisieran preservar su carácter pluralista deberían afirmar valores, entre los que el equilibrio deba alcanzarse mediante la ponderación con otros valores del mismo tipo, sin la participación del médium homologador y desnaturalizador del dinero

(Gustavo Zagrebelsky, El Derecho dúctil).

Ex-Constituyente de 1991. Ex-Magistrado del Consejo Superior de la Judicatura (1992-1999). Conjuez de la Corte Constitucional Colombiana (2004 a la fecha). Actualmente Decano de la Facultad de Derecho de la Universidad Santo Tomás de Bogotá. Magíster en Análisis Políticos, Económicos y Relaciones Internacionales, Universidad Externado de Colombia-Instituto de Estudios Políticos de París. Correo electrónico: alvaroecheverri@ usantotomas.edu.co 


\title{
Resumen
}

El texto analiza la problemática global que se presentan en los sistemas democráticos contemporáneos, relacionado con las transformaciones que vienen sufriendo la aplicación del Derecho Privado como consecuencia de la incorporación de los valores constitucionales a todo el resto del ordenamiento jurídico.

\section{Palabras clave}

Derecho Privado, Derecho Constitucional.

\begin{abstract}
This article examines the global issues that arise in contemporary democratic systems, related to the transformations that are undergoing the implementation of Private Law as a result of the incorporation of constitutional values to the rest of the law.
\end{abstract}

\section{Key words}

Private law, constitutional law.

\section{INTRODUCCIÓN}

La normatividad constitucional de los derechos, conformada por disposiciones, valores y principios contenidos en las constituciones, originalmente fue concebida $-\mathrm{y}$ así operó durante el siglo XIX $\mathrm{y}$ buena parte del XX-, como un conjunto de poderes de defensa del individuo (posiciones jurídicas) frente al Estado. La negativa experiencia del absolutismo monárquico infeccionó al liberalismo burgués de una desconfianza radical hacia el poder estatal. A éste se le atribuía una dinámica tendencial hacia el abuso y la arbitrariedad, lo cual inevitablemente conducía a la conculcación de los derechos inalienables del ser humano. "No se gobierna impúnemente", decía Saint-Just y Condorcet, a su vez, expresaba: "mientras menos se gobierne, mejor".

Los derechos -con el apelativo actual de fundamentales-, incorporados en los textos constitucionales, se erigen entonces como muro infranqueable a las ingerencias abusivas del poder político sobre la vida privada de las personas. Eran derechos, ante todo, de defensa del individuo por oposición al Leviathan estatal. Ciertas corrientes de la dogmática constitucional se niegan, todavía hoy, a recepcionar la validez de ciertos derechos prestacionales como obligaciones estatales por su adscripción a esta teoría que de manera excluyente sólo concibe los derechos fundamentales como posiciones jurídicas de defensa del individuo frente al Estado.

Sin embargo, el desarrollo de la economía capitalista ha engendrado fuerzas socio-económicas (empresas mono o oligopólicas, sectores bancario y financiero, etc.), las cuales, incluso, gozan de mayor poder y recursos que el propio Estado y con los cuales los individuos se relacionan en forma mucho más permanente y continua que con éste, en demanda de bienes y servicios mediante la realización de multitud de contratos de diverso tipo. Estas fuerzas, como lo demuestra la experiencia, en sus multiformas relaciones con las personas no están excentas de cometer abusos que atentan contra los derechos fundamentales de éstas.

Esta realidad apenas normal dentro del tráfago de los intercambios mercantiles se agrava cuando, en 
virtud de las corrientes neoliberales en boga, los Estados han terminado por entregar a empresarios del sector privado la prestación de servicios básicos para la garantía de la dignidad y la calidad de la vida humana, como son la seguridad social en su doble aspecto de atención a la salud y el régimen pensional, así como los servicios públicos domiciliarios.

Esta última circunstancia, pero no exclusivamente, justifica que nos ocupemos en este artículo de cómo las normas iusfundamentales (disposiciones, valores y principios) inscritas en la constitución protegen al ciudadano frente a otro ciudadano o frente a personas jurídicas de Derecho Privado. En estos casos se ven afectados, por la vía del legislador o de los jueces, ciertos contenidos de la legislación civil. Es lo que Robert Alexy (1986) ha denominado "el efecto horizontal" de las normas iusfundamentales precisamente por su capacidad de irradiación, sobre todo, el sistema jurídico.

\section{FUNDAMENTACIÓN TEÓRICA DEL PRINCIPIO DE IRRADIACIÓN}

El Tribunal Constitucional Federal Alemán buscó dar cuenta del "efecto de irradiación" sobre la totalidad del sistema jurídico apoyándose en el concepto de orden valorativo objetivo. Tribunal dice:

De acuerdo con la jurisprudencia permanente del Tribunal Constitucional Federal, las normas fundamentales contienen no sólo derechos subjetivos de defensa del individuo frente al Estado, sino que representan, al mismo tiempo, un orden valorativo objetivo que, en tanto decisión jurídico constitucional, vale para todos los ámbitos del derecho y proporciona

1 Siguiendo a Alexy, preferimos hablar de "Sistema Jurídico" y no de "Ordenamiento Jurídico". Si bien la expresión de "sistema" incorpora la noción de "orden" (ordenamiento), en el primero, los elementos y normas se organizan -valga la redundancia- de acuerdo con un elemento articulador que es la Constitución. Por tanto, la noción de sistema remite a la idea de organización de elementos, pero no de cualquier forma, pues los elementos tienen un "lugar" dentro del sistema gracias al elemento que los articula (para la discusión del término, ver Hernández et al., 1973, pp. 24-55). directrices e impulsos para la legislación, la administración y la justicia (las cursivas son nuestras) (BV ert GE, s.f., 198 [207]).

Los valores son bienes o cosas cuya cualidad esencial es servir a la realización de la dignidad humana y, por lo mismo, su efectivización asegura la convicencia social. Dichos valores son el producto del pacto fundacional que se materializa por medio de una constitución. Por ejemplo, la constitución política colombiana en su Preámbulo consagra valores como la vida, la convivencia, el trabajo, la justicia, la igualdad, el conocimiento, la libertad y la paz. Desde luego, esta enunciación no agota la existencia de otros valores que se encuentran a lo largo de su texto y que con los del Preámbulo conforman ese orden valorativo constitucional, del que habla el Tribunal Alemán.

El carácter objetivo de este orden de valores, a mi juicio, se desprendería de su simple consagración en el texto constitucional, del cual se deriva su fuerza vinculatoria para todos las autoridades y los particulares por razón de la naturaleza normativa superior que posee la constitución (Constitución Política de Colombia, 1991, Arts. 4 y 6).

Siguiendo a Alexy (1997, p. 509), se puede decir que lo objetivo del orden valorativo constitucional resulta de abstraer todo lo subjetivo, un poco a la manera del "velo de la ignorancia" de Rawls, de suerte que lo valores no se pueden predicar como intereses de grupos, clases o personas particulares de la sociedad. Por ello, el mismo Alexy los llama "Principios de nivel supremo de abstracción", lo cual en un lenguaje más común al análisis constitucional se denominan "decisiones básicas jurídico-constitucionales" o "normas básicas que definen valores".

Ahora bien, las constituciones contemporáneas no sólo sirven a la organización del poder político, definiendo las instituciones políticas básicas, las funciones que éstas cumplen y los mecanismos para su conformación, sino que también, a través 
precisamente de ese orden valorativo objetivo, se sientan las bases del Estatuto básico de organización de la sociedad civir. Esto explica, desde ya, su fuerza expansiva hacia todo el sistema jurídico.

Esa fuerza expansiva sobre todo el sistema jurídico puede tener:

- Un efecto mediato, con respecto a toda interpretación de una norma de derecho privado y que, en casos especiales, puede llegar inclusive a justificar una decisión contraria a la ley. Por ejemplo, la aceptación por los jueces competentes colombianos de procesos de divorcio de matrimonios católicos cuando la ley solamente los autorizaba para los matrimonios civiles, tal como ocurrió en Colombia a partir de la Constitución de 1991, en cumplimiento del mandato del Art. 42 de la ley fundamental que prevee que la disolución del vínculo matrimonial se rige por la legislación civil.

- Efecto inmediato: se considera que del orden valorativo objetivo constitucional se derivan derechos privados subjetivos por razón de la propiedad de dicho orden de ser derecho plenamentevinculante. Envirtud de este efecto inmediato, la Corte Constitucional colombiana, por ejemplo, ha derivado derechos patrimoniales para las uniones homosexuales permanentes

Por tanto, el hecho de que las normas iusfundamentales, en cuanto conforman un orden objetivo de valores, sean obligatorias en todos los ámbitos del Derecho estatal, "implica que el Estado está obligado a tenerlas en cuenta tanto en la legislación civil como en la jurisprudencia civil" (Alexy, 1997, p. 516).

2 Ese estatuto básico de la sociedad civil contenido en la Constitución, incorpora disposiciones que obligan a las diversas asociaciones de la sociedad civil (sindicatos, cooperativas, empresas, asociaciones vecinales y comunitarias, etc.), a regirse por principios democráticos en la elección de directivos y en la toma de decisiones. Con respecto a la empresa privada garantiza la libertad de empresa, pero con responsabilidad social. Igualmente, imparte directrices para evitar los abusos de las posiciones dominantes en el mercado, etc.
Así quedó formulado en el célebre fallo Lüth del Tribunal Constitucional alemán que permitió la ampliación del recurso de amparo para la protección de los derechos fundamentales a los casos en que la afectación de éstos proviniera de un particular y cuando tal afectación hubiera sido sancionada como válida mediante fallo de la jurisdicción civil.

Dijo entonces dicho Tribunal:

Por mandato consticional, el juez debe examinar si las prescripciones materiales de derecho civil que tiene que aplicar están influenciadas iusfundamentalmente en la manera descrita; si tal es el caso, entonces en la interpretación y en la aplicación de estas prescripciones, tiene que tener en cuenta la modificación del derecho privado que de aquél resulta (las cursivas son nuestras) (Schwabe, 2003, pp. 133 y ss.).

Ahora bien, es claro que la irradiación del orden de valores de la constitución a todo el sistema jurídico no puede determinar los contenidos concretos de cada área del Derecho ordenario, pero, sí puede -como sostiene Alexy- exigir unos contenidos iusfundamentales como necesarios y excluir otros como iusfundamentales imposibles o inaceptables. Esto también vale para las competencias del "particular para crear deberes jurídicos a través de contratos" (Schawabe, 2003, p. 525).

En definitiva, podremos decir que el sistema jurídico es un sistema de elementos normativos organizados -que es a lo que alude precisamente la noción de sistema-, siendo la constitución el elemento determinante para esa organización y el que asigna el "lugar" que a cada normatividad le corresponde. $\mathrm{O}$ en palabras del mismo Alexy: "Con esto, el sistema jurídico, debido a la vigencia de las normas iusfundamentales, tiene el carácter de un sistema jurídico materialmente determinado por la constitución" (las cursivas son nuestras) (Alexy, 1997). 


\section{CRITERIOS DE RAZONABILIDAD PARA LA APLICACIÓN DE LA IRRADIACIÓN DEL DERECHO CONSTITUCIONAL AL DERECHO PRIVADO}

Sin duda, la irradiación del orden objetivo de valores constitucionales al ámbito del Derecho Privado encuentra un primer obstáculo en el principio de la autonomía de la voluntad que gobierna el orden normativo privado.

El principio de autonomía de la voluntad tiene como consecuencia la definición del carácter restringido y excepcional de la intervención del Estado en la regulación de las relaciones privadas, de suerte que tal intervención sólo se justifica cuando exista una razón política o jurídica plenamente válida. Tal tipo de razones se configuran cuando:

- Se pacten cláusulas contractuales contrarias al orden público o a una previsión legal expresa ${ }^{3}$.

- Se pretende abusar de una especial posición (dominante) en el mercado ${ }^{4}$.

- Se intente imponer cláusulas abusivas.

- Se configuren mecanismos de engaño, confusión o abuso al consumidor ${ }^{5}$.

- Se empleen mecanismos de organización societaria que pudieran tener como efecto la afectación de intereses de los acreedores ${ }^{6}$.

3 El Art. 50 del Dto. 2153 de 1992, prohibe la disminución de precios por debajo de los costos cuando ello tenga por objeto eliminar a uno o varios competidores o prevenir la extensión o expansión de estos.

4 Por ejempo, la exigencia de las aseguradoras de presentar sentencia condenatoria que demuestre la responsabilidad de un tercero para proceder a pagar un seguro, es una cláusula abusiva en concepto de la Corte Suprema Colombiana en su Sala Civil.

5 Esto conlleva a que los productores, por ejemplo de medicamentos, deben expresar en el empaque de sus productos de manera claramente legible las indicaciones de sus componentes, los efectos para la salud, las formas correctas de utilización y las contraindicaciones respectivas (Dto. 3466, Art. 17).

6 Por ejemplo, la prohibición del Art. 262 del Código del Comercio Colombiano de la llamada "imbricación", de acuerdo con la cual las sociedades subordinadas no podrán tener, a ningún título, partes de interés, cuotas o acciones en las sociedades que las dirigen y controlan.
Ahora bien, a las causales de intervención regulatoria estatal se le debe agregar el carácter vinculante del orden valorativo constitucional en aquéllas circunstancias en las cuales se encuentren comprometidos, en forma clara e inequívoca, directa o indirectamente, disposiciones, valores o principios iusfundamentales (Calderón V., s.f.).

El problema que plantea esta nueva causal de intervención estatal regulatoria de la autonomía privada tiene que ver con el cuándoy en qué casos una relación conflictual, nacida de una relación privada, sin dejar de ser tal, adquiere relevancia constitucional, lo que obliga a los agentes jurídicos (legislador o juez) a tener en cuenta el orden valorativo constitucional para la interpretación y aplicación de la norma civil o para su modificación, si fuere del caso.

En este punto se impone establecer unos márgenes razonables de intervención, de suerte que se respete el principio de autonomía privada, al tiempo que se entienda que esta autonomía está sometida con carácter vinculatorio a la Constitución $y$, en particular, a los derechos fundamentales (Constitución Política de Colombia, Art. 6). Porque, como dice Robert Alexy "una constitucionalización adecuada sólo puede construirse por el camino arduo y pedregozo de la dogmática de los márgenes de acción" (las cursivas son nuestras) (2003, citado en Calderón V., s.f.).

La dogmática de los "márgenes de acción" plantea que la constitución, desde la perspectiva de su fuerza vinculante, se mueve en dos niveles distintos de concreción:

- Como orden fundamentalque de manera clara e inequívoca, vincula a los poderes y órganos del Estado.

- Como marco de principios y valores que proporcione orientaciones y directrices generales a las autoridades y a los particulares en la inter- 
pretación y aplicación de toda la normatividad vigente, incluida la civil.

En este último nivel, la constitución no proporciona soluciones a todos los problemas jurídicos posibles, tan solo define: 1) qué es lo constitucionalmente necesario y deseable; 2) lo que constitucionalmente no es posible o que estaría prohibido y 3) qué es lo que constitucionalmente sería discrecional o permitido.

Como se ve, la dogmática de los márgenes de acción no proporciona soluciones específicas al problema de la constitucionalización del Derecho ordinario y, en particular, del Derecho Privado. Su operancia se mediría en cada caso concreto, así:

- Todo problema jurídico tiene su origen en un conflicto de intereses que buscan justificarse en posiciones jurídicas reconocidas como derechos.

- De acuerdo con la dogmática de los márgenes de acción, se buscaría establecer en los litigios de naturaleza privada si el asunto tiene relevancia constitucional. Esto es, si involucra disposiciones, valores o principios iusfundamentales. Si no es así, el conflicto de intereses puede ser resuelto mediante la interpretación y la aplicación de las normas del Derecho Privado.

- En caso contrario, la normatividad privada se debe reeler a la luz de la normatividad iusfundamental. Esta relectura no siempre es fácil para el interprete en virtud de la generalidad, vaguedad e, incluso en ocasiones, contradicciones que posee el texto constitucional. Es lo que Ilaman eufemísticamente algunos constitucionalistas, siguiendo a H.L. Hart (1961, pp. 168-169) y a Ronald Dworkin (1984), “La textura abierta de las normas". Para otros más críticos, como el alemán Mattias Herdegen, profesor de la Universidad de Bonn, las normas valorativas y de principios contenidas en el texto constitucional son los "himnos constitucionales" que como "manzanas envenenadas son regaladas por un constituyente con humor lírico al juez constitucional" (1995, p. 39).

Sin duda, éstos son los problemas y los riesgos de una constitución que pretenda eregir un orden valorativo y de principios que rijan y orienten la vida del Estado y la sociedad.

Pero, como acertadamente lo reconoce el mismo Mattias Hardegen, es al juez constitucional y más específicamente, al interprete "supremo y último" de la constitución (el Tribunal Constitucional) al cual corresponde de manera privilegiada -esa precisamente es su función- la interpretación acerca del contenido y alcance de las normas iusfundamentales. De lo esto surge la necesidad y obligatoriedad del precedente constitucional como mecanismo de interpretación y aplicación uniformes de dicha normatividad para todos los jueces y tribunales, sobre todo, en aquéllos sistemas jurídicos -como el colombiano-, en los cuales las decisiones de la Corte Constitucional en asuntos particulares carece de fuerza vinculante general y en los cuales otros tribunales (Corte Suprema, Consejo de Estado) se repuntan de igual jerarquía al juez de la constitución $y$, por tanto, no se sienten vinculados por sus decisiones. Problemática a la cual sólo aludimos de pasada por no ser el tema central de este artículo.

- Casos más difíciles resultan ser aquéllos, en los cuales, existiendo un comprometimiento en el asunto de naturaleza civil de las normas iusfundamentales, éstasno ofrecen unasolución clara y precisa, llevando incluso al interprete constitucional auténtico (el tribunal constitucional) a adoptar decisiones contrapuestas. En tales casos, cabe pensar que se entra en el terreno de lo permitido o al menos tolerado por la constitución y la relectura de la normatividad civil hecha por el interprete; se deberá acoger a este margen de acción. 
Ahora bien, ¿ cómo identificar si un asunto que prima facie se presenta como de naturaleza civil, posee o no relevancia constitucional, obligando, en consecuencia, a tener en cuenta la normatividad iusfundamental? Pienso que para ello debe operar en el agente jurídico (legislador o juez) una cierta sensibilidad constitucional o "sentimiento constitucional", como lo denomina Karl Loewestin. Esto es, un conocimiento claro por parte del interprete y del aplicador de la norma del orden valorativo contenido en la Constitución y su compromiso inequívoco con su materialización efectiva?

Por otra parte, parecería en apariencia más sencillo identificar el involucramiento de la normatividad iusfundamental en el caso de las empresas privadas a las cuales ha delegado el Estado la prestación de servicios públicos esenciales.

Aquí -es lo que ha ocurrido en el caso colombiano-, se ha producido un desplazamiento del derecho accional en cuanto a los términos y cumplimiento de los contratos civiles por las acciones constitucionales de protección de los derechos fundamentales de naturaleza individual a través de la acción de amparo o de derechos colectivos mediante las llamadas acciones colectivas o de grupo.

El fenómeno tiene una clara explicación, pues resulta evidente que en el caso, por ejemplo, de las empresas prestadoras del servicio de salud está involucrado el derecho fundamental a la vida, el cual, frente a situaciones límite -enfermades terminales o catastróficas, exigencias de tratamientos o medicamentos costosos para la conservación de la vida- no puede quedar sometido a las prescripciones contractuales civiles, de cuya aplicación

$7 \quad$ Karl Loewestein, en su Teoría de la Constitución (1976, p. 200) describe el "Sentimiento Constitucional", como aquella conciencia de la comunidad que, transcendiendo a todos los conflictos y tensiones existentes en ella, integra a detentadores y destinatarios del poder político en el marco de un orden comunitario obligatorio establecido en la constitución y que, por tanto, regula todas sus relaciones políticas y sociales. práctica se puede derivar el desconocimiento de derechos fundametnales. Una situación parecida se puede presentar en el caso de las empresas privadas que administran fondos pensionales o entidades públicas o privadas encargadas de reconocer el beneficio pensional, dado que en las decisiones que ellas toman resultan comprometidos, la mayoría de las veces, el derecho a una vida digna cuando ya no se está en capacidad de adelantar una actividad laboral o las exigencias del derecho a un "mínimo vital", establecido como parámetro por la Corte Constitucional para la liquidación de las mesadas pensionales, derechos que no encuentran protección adecuada en los trámites procesales de naturaleza civil.

Por otra parte, las empresas de servicios públicos domiciliarios, particularmente las que prestan el servicio de agua potable y alcantarillado y que actuan con el criterio de maximización de la rentabilidad, se ven obligadas, por encontrarse involucrado en la prestación de esos servicios, a proteger el derecho a la salud en conexión con el derecho fundamental a la vida, a modular sus tarifas de acuerdo con el principio constitucional de solidaridad, a fin de favorecer a los sectores más vulnerables con cobros más bajos o a extender sus servicios a áreas o regiones deprimidas que carecen de éstos, lo cual implica, en general, altos costos en el tendido de las redes, las cuales, sin duda, afectan los margenes de rentabilidad de dichas empresas.

Aquí, como en el caso de las empresas que prestan los servicios en materia de salud, el criterio de la obtención de un lucro por razón de una actividad entendida como comercial, se ve sometido al orden valorativo de la Constitución, lo cual obliga a la modificación de normas contractuales de derecho privado o a la reorientación de dicha actividad en el sentido querido por la Constitución. Ahora bien, en general, se podría sostener que en los conflictos de intereses de naturaleza civil que comprometan valores y principios constitucionales y a los cuales 
se debe atener el juez para su resolución, siguen siendo, con todo, conflictos de Derecho Privado.

En otros casos, las actividades comerciales privadas, como las que cumplen las ya mencionadas empresas prestadoras de servicios de salud o las administradoras de pensiones, lo mismo que las que prestan servicios públicos domiciliarios, en razón de un más intenso compromiso con los derechos fundamentales, los conflictos derivados de su objeto social sufren una máxima constitucionalización, no sólo desde el punto de vista argumentativo, sino también desde lo procedimental, a través de acciones constitucionales -esto es, previstas en la propia Constitución-, las cuales han terminado reemplazando y sustituyendo los trámites procesales civiles.

\section{UN CASO EXTREMO DE IRRADIACIÓN}

En el contexto de la crisis de 1998 en el sector bancario colombiano, dedicado al financiamiento mediante créditos a largo plazo para la adquisición de vivienda, como consecuencia de la decisión gubernamental de atar dichos créditos con garantía hipotecaria al interés comercial vigente -que durante ese periodo se elevó a tasas hasta del $70 \%-$, se produjó una masiva cesación de pagos y la pérdida de sus viviendas -cuyo valor había venido siendo amortizado, para cerca de $\mathbf{8 0 0 . 0 0 0}$ familias-; en ese contexto la Corte Constitucional declaró inconstitucionales las normas de creación del sistema de financiamiento para adquisición de vivienda conocido como UPAC (unidad de pago de valor constante), por considerar que éste atentaba contra el derecho fundamental de acceder a una vivienda digna, consagrado en el Art. 51 de la Ley fundamental.

Dicha declaración se produjó en el efecto diferido, esto es, que la normatividad declarada contraria a la Constitución permanecería vigente hasta tanto el Congreso de la República expidiera una ley que reglamentara nuevamente los sistemas de financiamiento para la adquisición de vivienda, de acuerdo con los parámetros y directrices que la misma Corte fijaba en su sentencia (Corte Constitucional, Sentencia C-481 de 1999).

Expedida la ley incitada (Ley 546 de 1999) que creaba un nuevo mecanismo de financiación denominado UVR, la Corte Constitucional declaró la constitucionalidad condicionada por parte de dicha norma por no haberse señalado un tope máximo para los intereses remuneratorios de los créditos de vivienda, señalando, además, que éstos deberían corresponder o ser iguales a los créditos cuyos intereses fueran los más bajos del mercado.

Con esta decisión, la Corte no sólo limitó la libertad de empresa del sector financiero, dedicado al otorgamiento de crédito para adquisición de vivienda, sino también la libertad contractual entre particulares.

Vale la pena detenerse brevemente en los argumentos del Tribunal Constitucional colombiano:

Por ser el acceso a la vivienda digna un derecho de rango constitucional que el Estado debe hacer efectivo (Art. 51 C.P.) por haberse establecido como objetivo prevalente en la Constitución de 1991 la democratización del crédito (Art.335 C.P.), según los lineamientos del Estado Social de Derecho (Art. $1^{\circ}$ C.P.), las tasas aplicables a los créditos de vivienda deben ser intervenidos por el Estado; no pueden ser pactados por los contratantes en un plano de absoluta autonomía por cuanto su determinación según las fluctuaciones del mercado hace posible que las instituciones financieras, prevalidas de su posición dominante impongan a sus deudores tasas $y$ márgenes de intermediación excesivamente altos, haciendo negatorios sus derechos constitucionales a la vivienda y al crédito...

Es un hecho publicamente conocido que los deudores de las entidades crediticias no pactan en realidad con ellas las tasas de interés, ni las discuten, y que, por el 
contrario, en una posición de absoluta indefensión, los intereses son impuestos, de modo que deben optar sin ningún remedio, entre aceptarlos o no tomar el préstamo, ya que suscriben contratos de adhesión. Es allí donde aparece la función interventora del Estado que está llamado a fijar topes a las tasas de interes que se cobran y velar porque esos topes se respeten.

Para la Corte, la total falta de restricción en la fijación de las tasas de interés en materia de vivienda viola el principio de un orden justo como valor primordial del preámbulo de la Constitución, y lesiona el patrimonio de los deudores...

Los intereses desbocados, sin control ni medida, rompen el equilibrio mínimo entre las partes y hacen imposible que el deudor cancele la obligación contraida.

Por otra parte, el empresario financiero, mediante esa remuneración desmedida... resulta enriqueciéndose sin causa y empobreciendo injustificadamente al deudor (Corte Constitucional, Sentencia C-955 de 2000).

Independientemente de las deficiencias técnicas de la argumentación de la Corte, más de tipo sociológico que jurídico -lo cual no sería inválido si el razonamiento sociológico hubiera estado acompañado de un razonamiento jurídico con fundamento en la aplicación de la técnica de ponderación de derechos, en este caso, la Libertad de Empresa vs. el acceso a una vivienda digna (Arango R., 2004, p. 170 y ss.)-, la pregunta que surge es: ¿hasta dónde puede llegar el Juez Constitucional en su capacidad de hacer irradiar el orden valorativo constitucional al resto del sistema jurídico, sin desplazar o sustituir a los agentes responsables de definir y ejecutar las políticas públicas, esto es, al legislativo y al ejecutivo?

La teoría de "los márgenes de acción" de Alexy no parecen ayudar mucho en sociedades como las nuestras, con profundos desequilibrios sociales y en las cuales la fórmula política de la Constitución del "Estado Social de Derecho" se manifiesta ape- nas como una simple expresión retórica para los gobiernos de turno; por tanto, le corresponde a los tribunales constitucionales la ingente tarea de hacerlo realidad. Desde esta posición, estos tribunales se adentran inevitablemente en la función de intervenir en la definición de las políticas públicas por la inacción o insuficiencia de los gobiernos y de los órganos legislativos en su tarea de materializar el orden de valores consagrado en la Constitución, en el entendido de que su papel de defensa de la Constitución no se circunscribe simplemente a garantizar el orden competencional definido para los distintos órganos del Estado por la Constitución, sino que además deben buscar la materialización de los derechos fundamentales consagrados en ella.

\section{CONCLUSIONES}

- Las constituciones contemporáneas, en general, incorporan un ordenvalorativo objetivo, que en razón de su carácter normativo está llamado a influir en todo el sistema jurídico, incluida la normatividad jurídica de naturaleza privada.

- Además, ese orden valorativo suele incorporar verdaderos mandatos o disposiciones que rigen para la sociedad civil, como por ejemplo, el régimen democrático que debe presidir la organización y el funcionamiemto de las asociaciones privadas; la libertad de empresa con función social; la prohibición de abuso de posiciones dominantes; la preservación de un medio ambiente sano; las limitaciones a la propiedad privada por razón de su función social o ecológica, etc. Todo ello proporciona un cuadro de derechos y obligaciones de la sociedad civil que constituye su verdadero estatuto y que, en consecuencia, fuerza a la legislación privada a acomodarse a sus prescripciones.

- El orden valorativo constitucional, que obligatoriamente debe ser tenido en cuenta por el legislador o el Juez, según el caso, a riesgo no sólo de violar la Constitución, sino también de afectar derechos fundamentales, no siempre 
es fácil de discernir por razón de la naturaleza amplia, génerica y contradictoria que a veces ostenta la normatividad iusfundamental.

- De ahí, el papel central que corresponde al Tribunal Constitucional para definir el alcance de irradiación de ese orden valorativo al resto del ordenamiento jurídico.

- Para el legislador o el juez se hace necesario que en cada caso concreto de naturaleza privada se establezca si el asunto tiene relevancia constitucional en razón a los principios o derechos comprometidos en éste, a fin de efectuar una relectura de la legislación civil a la luz del orden valorativo constitucional, que puede conducir, inclusive, a la modificación de la legislación para alcanzar una solución permitida o admisible por la ley fundamental.

- Algunas actividades privadas que inequivocamente afectan la realización de derechos fundamentales, como en loscasos delaprestación de los servicios de salud, pensiones, servicios públicos, domiciliarios esenciales, obligan a unamáximaconstitucionalizacióndelDerecho Privado para acomodarlo a la normatividad iusfundamental no sólo desde el punto de vista argumental, sino incluso procedimental.

- El papel del Tribunal Constitucional, como garante de los principios iusfundamentales no deja de generar controversias cuando éste interviene en el diseño de las políticas públicas que afectan de manera directa la autonomía privada, que es el fundamento de la legislación civil.

- La solución a este problema, que es inevitable para el caso de constituciones con un alto contenidovalorativo, pasa no sólo por laaplicación de fórmulas de ingeniería constitucional, sino también por la voluntad y el compromiso de Ios demás órganos estatales y de los propios ciudadanos, de realizar plenamente, esto es, contodassusconsecuencias, lafórmulapolítica del Estado Social y Democrático de Derecho consagrado en la ley fundamental.

\section{REFERENCIAS}

Acosta, J. (2008). El nuevo orden contractual colombiano. Cuadernillos avances.

Arango R., R. (2004). Derechos, constitucionalismo y democracia. Bogotá: Universidad Externado de Colombia.

Alexy, R. (1997). Teoría de los derechos fundamentales. Madrid: Centros de Estudios Constitucionales.

Alexy, R. (2003). Tres escritos sobre derechos fundamentales y teoría de los principios. Bogotá: Universidad Externado de Colombia.

Calderón V., J.C. (Sin fecha). Constitucionalización del derecho comercial. Universidad de Caldas.

Corte Constitucional de Colombia, Sentencia C-481 de 1999.

Corte Constitucional de Colombia, Sentencia C-955 de 2000.

Dworkin, Ronald. (1984). Los derechos en serio. Barcelona: Ariel.

Hardegen, M. (1995). La jurisprudencia constitucional en el derecho comparado. En Anuario de derecho constitucional latinoamericano. Bogotá: Fundación Konrad Adenauer.

Hart, H.L. (1961). El concepto de Derecho. Buenos Aires: Abeledo-Perrot.

Loewestein, K. (1976). Teoría de la Constitución. Barcelona: Ariel.

Schewabe, J. (2003). Cincuenta años de jurisprudencia del Tribunal Constitucional Federal Alemán. Bogotá: Gustavo Ibáñez, Fundación Konrad Adenauer. 